\title{
Wayfinding Design: Sistema de sinalização para o Mercado Central de Pelotas/RS
}

\author{
Wayfinding Design: Signage System \\ to the Central Market in Pelotas/RS
}

\author{
Nathália Santos Fick ${ }^{[1]}$, Rafael Klumb Arnoni ${ }^{[2]}$
}

Resumo: $O$ artigo aborda o desenvolvimento e resultados do projeto realizado como componente prático do Trabalho de Conclusão de Curso, no qual foi desenvolvido um Sistema de Sinalização para o Mercado Central de Pelotas/RS, considerando os conceitos e práticas relacionadas ao Design de Sinalização e Wayfinding Design. Justifica-se por contribuir para a orientação espacial do local através da organização das informações do ambiente por meio de elementos visuais que auxiliam no deslocamento e contribuem para o bem-estar e segurança dos usuários do Mercado. Utilizou-se a metodologia proposta por Gibson (2009) para o desenvolvinto de estratégias de Wayfinding em projetos de sinalização. Como resultado, obteve-se uma proposta de Sistema de Sinalização e a concepção do Manual de Sinalização e Wayfinding.

Palavras-chave: Sistema de Sinalização. Wayfinding Design.

Mercado Central de Pelotas.

\begin{abstract}
This paper presents the results of the project carried out as a practical component of the Course Conclusion Work, in which was developed a Signage System for Central Market in Pelotas/RS, considering the concepts and practices related to Signage and Wayfinding Design. It is justified by collaborating with spatial orientation through the organization of information about the environment through visual elements that help in the displacement and contribute to the well-being and safety of market users. Was used the method proposed by Gibson (2009), which deals with the use of Wayfinding strategies in signaling projects. As a result, a proposal for a Signage System and the conception of the Signage and Wayfinding Manual were obtained.
\end{abstract}

Keywords: Signage System. Wayfinding Design. Pelotas Central Market.

[1] Bacharela em Design, IFSUL. nathaliiasfick@gmail.com

[2] Mestre em Memória Social e Patrimônio

Cultural, UFPEL.rafaelarnoni@ifsul.edu.br 


\section{INTRODUÇÃO}

Os Mercados Públicos desempenharam um papel fundamental no cotidiano das cidades brasileiras, centralizando o comércio de vendas e trocas de mercadorias, como produtos oriundos de agricultores e de criadores de animais, os mais diversos alimentos. Com o passar do tempo e o surgimento dos supermercados, hipermercados e shoppings centers, os mercados perderam parte de sua força e passaram a ocupar um papel mais ligado ao patrimônio e turismo dentro do espaço urbano. $\mathrm{Na}$ cidade de Pelotas/RS o Mercado Central permanece com suas atividades de comércio e serviços, com um perfil diferente do que fora há alguns anos. Este novo perfil transformou-o em um espaço voltado para o turismo, gastronomia e cultural popular.

O prédio do Mercado Central de Pelotas (MCP) faz parte do conjunto arquitetônico tombado pelo IPHAN (Instituto do Patrimônio Histórico e Artístico Nacional) como Patrimônio Nacional e parte integrante da rota turística e histórica da cidade de Pelotas.

Em um primeiro momento, observaram-se dificuldades de orientação na parte interna da edificação, muito em razão da planta simétrica do local, o que o torna muito similar seus espaços internos. Através destas constatações iniciais, realizadas por meio de observação não-participante, entrevistas e questionários, percebeu-se que os usuários têm dificuldade para se localizar dentro do prédio, geralmente necessitando dar muitas voltas pelo local até chegar ao seu objetivo.

O Mercado possui uma configuração retangular com travessas em forma de cruz que ligam suas quatro entradas, dividindo-se internamente em quatro partes iguais, o que torna o a parte interna do Mercado muito parecida em todas as suas vistas e, consequentemente, confuso se não houver o auxílio de meios de sinalização. Neste sentido, um dos motivos que levou ao desenvolvimento do projeto diz respeito a necessidade de um Sistema de Sinalização adequado para o MCP por ser um espaço que está localizado na parte central da cidade sendo um marco importante e muito frequentado tanto para compras quanto para visitação. 
O projeto se delimitou ao estudo das questões que englobam o Design de Sinalização mais especificamente voltado para ao Wayfinding, com o intuito de tornar mais eficiente e segura a circulação dos usuários no Mercado Central de Pelotas, propondo um sistema que auxilie neste processo. Sendo assim, no decorrer dos estudos, constatou-se de que forma um Sistema de Sinalização, através de práticas projetuais, pode contribuir para a valorização turística e cotidiana do Mercado Central de Pelotas. Segundo Scherer (2017):

A sinalização quando bem projetada é reconhecida como um dos principais contribuintes para o aumento do bem-estar e segurança; para a ambientação, que tem importância pela sua capacidade de criar um senso de lugar para determinado espaço, e pelo seu poder de reforçar uma imagem de marca. (SCHERER, 2017, p.94)

Com o propósito de guiar o estudo e desenvolvimento do projeto, foi utilizada a metodologia proposta por Gibson (2009). Segundo o autor, mesmo que cada projeto tenha suas características particulares, é possível prever um padrão hierárquico e estrutural que se aplica facilmente em projetos distintos de Wayfinding. A metodologia proposta pelo autor é constituída por três etapas gerais: Planejamento, Design e Implementação, sendo que cada uma dessas é subdividida em etapas menores. $O$ autor propõe diretrizes e entregáveis para cada etapa, que foram adaptadas para as necessidades deste projeto conforme o Quadro 1.

Quadro 1 - Adaptação da Metodologia de Gibson (2009) para este Projeto.

PLANEJAMENTO

\section{PESQUISA E ANÁLISE}

- Levantamento de informações do Mercado Central: Histórico, usos do local, sinalização atual;

- Revisão bibliográfica acerca dos temas pertinentes para a elaboração do projeto;

- Observação e levantamento fotográfico do local;

- Entrevistas com usuários e trabalhadores do local;

- Análise de similar.

\section{DESIGN}

DESENHO ESQUEMÁTICO

- Definição do conceito visual;

- Escolha de paleta de cores;

- Elaboração de pictogramas;

- Escolha tipográficas;

- Definição dos materiais a serem utilizados;

- Esquema de construção.
IMPLEMENTAÇÃO

ORÇAMENTOS E

FABRICANTES

Por se tratar de um trabalho

de projeto acadêmico, esta

etapa será desconsiderada. 
ESTRATÉGIA

- Escolha das técnicas que serão utilizadas;

- Organização do ambiente.
DESENVOLVIMENTO

- Desenvolvimento das peças gráficas.

\author{
ADMINISTRAÇÃO \\ E CONSTRUÇÃO \\ Por se tratar de um trabalho \\ de projeto acadêmico, esta \\ etapa será desconsiderada.
}

PROGRAMAÇÃO

- Definição do conceito-chave;

- Definição dos fluxos;

- Escolha da posição das placas
DOCUMENTAÇÃO E

FABRICAÇÃO

- Elaboração do Manual de sinalização;

- Especificações técnicas;

- Produção de mockups.

\section{REFERENCIAL TEÓRICO PARA SISTEMAS DE SINALIZAÇÃO}

Inicialmente é preciso considerar que não há uma nomenclatura única que designe tal campo do conhecimento. É possível identificar termos distintos que são utilizados por estudiosos da área, tais como as definições encontradas em línguas estrangeiras: Wayfinding e Señalética. Suas distinções também ocorrem na forma como são conceituadas. Por conta disso, é fundamental entender quais são estas definições e utilizar a mais adequada ao projeto em questão. De modo geral, independente do termo adotado, o principal objetivo da sinalização é viabilizar e otimizar o funcionamento de determinado espaço para seus usuários. Neste artigo serão abordadas apenas as definições que foram utilizadas para guiar o projeto, que são: Design de Sinalização e Wayfinding Design.

\subsection{DESIGN DE SINALIZAÇÃO}

Em relação à Design de Sinalização, a SEGD - Society for Environmental Graphic Design dos Estados Unidos, dentro dos sistemas gráficos para ambientes, define o processo de si- 
nalização como o planejamento, projeto e especificação dos elementos gráficos no ambiente construído ou natural (Sociedade de Design Gráfico Ambiental apud. CARDOSO et. al., 2011). Sendo assim, estes elementos são usados como forma de comunicar informações especificas dentro dos sistemas de identificação, informação, direção, interpretação, orientação, regulamentação e ambientação.

Segundo D'Agostini:

Design de Sinalização é mais do que o simples projeto de comunicação visual para um ambiente: é, antes de tudo, um meio de organizar e pensar a relação entre os espaços construídos, seus usuários, a tecnologia de materiais e os processos de fabricação, além da própria comunicação. (D'AGOSTINI, 2017, p.26).

Para Chamma e Pastorelo (2008) a sinalização deve ser intuitiva para o usuário, como se ela adivinhasse o que o receptor deseja saber. Deve, antecipar-se às demandas, oferecendo informações precisas, permitindo que o usuário saiba facilmente tomar uma decisão. De acordo com Baumann (2010), o deslocamento dos usuários em espaços contruídos, podem ser influenciados por: pontos de referência (marcos, estátuas, obras de arte, edificações, sinalização); dispositivos de orientação (mapas de navegação no qual mostrem o que tem em seu entorno e indiquem como chegar ao seu destino e o tempo para tal) e a navegação (estratégia de direcionamento para se locomover do ponto $\mathrm{A}$ ao ponto $\mathrm{B}$ ).

\subsection{WAYFINDING DESIGN}

Sobre Wayfinding Design, Gibson (2009) comenta que milhares de pessoas são atraídas para centros urbanos e locais públicos, que proporcionam espaços de convivência entre indivíduos que trabalham, residem, ou utilizam para lazer dentre outros. Por conta disso, o autor afirma que há diversos caminhos e trajetos que o indivíduo pode escolher para percorrer até chegar a um determinado local, havendo grandes chances 
de desorientação dos usuários que utilizam estes locais públicos. Logo, o autor defende que estes locais devem conter informações suficientes para que as pessoas entendam o trajeto intuitivamente, nomeando essa técnica de orientação de Wayfinding Design. Ainda segundo o Gibson (2009), tal sistema atribui ao local uma linguagem global de informações, por meio de sinais e pontos de referência, proporcionando, assim, um sistema de orientação preciso e de rápido entendimento.

Segundo Locatelli (2007), em ambientes construídos como o Mercado Central de Pelotas, "quando a deficiência é arquitetônica, as dificuldades na orientação podem ser atribuídas a um layout confuso, difícil de ser compreendido e que, portanto, não pode ser completamente compensado por alguma sinalização" (LOCATELLI, 2007, p. 51). Com isso, a familiaridade com o local acaba por facilitar o deslocamento aos usuários mais habituados que utilizam seu próprio mapa mental armazenado na memória para traçar o trajeto a ser percorrido. Os menos habituados utilizam uma demanda maior de dispositivos de informação do local, como mapas e sinalização.

\section{DESENVOLVIMENTO DO PROJETO}

Nesta seção estão registradas as etapas desenvolvidas ao longo do projeto. Inicialmente é apresentado um breve histórico sobre o Mercado Central de Pelotas, após estão registrados os apontamentos referentes as entrevistas, questionário e levantamento fotográfico. Em seguida, a análise da sinalização atual do Mercado Central de Pelotas e a análise comparativa de similar correspondente a sinalização do Mercado Municipal de Curitiba. Depois estão registradas as etapas de elaboração projetual contendo as estratégias de organização do ambiente, orientação e indicação de bancas. Logo, encontra-se a etapa de proposta gráfica, contendo o conceito, painel de inspiração, relação da sinalização com a identidade arquitetônica do Mercado seguido dos estudos de proporção, grid e diagramação, a definição da paleta de cor, tipografias 
e elaboração de pictogramas. Por fim, a etapa de desenvolvimento dos modelos de sinalização, layout e mockup, seguido do desenvolvimento da documentação que contém as diretrizes para a implementação do projeto.

\subsection{PESQUISA E LEVANTAMENTOS}

A etapa inicial do Projeto de Sinalização diz respeito aos levantamentos e pesquisas realizadas a fim de embasar as decisões para a etapa de criação e desenvolvimento. Foram utilizados cinco instrumentos para coleta de dados: pesquisa bibliográfica, entrevistas semiestruturadas, análise do Mercado Central de Pelotas; análise comparativa de similar; observação não-participante. Estes instrumentos permitiram recolher diversos tipos de informações, descritos brevemente a seguir.

\subsubsection{Histórico do Mercado Central de Pelotas}

O Mercado Central está localizado na Praça Sete de Julho, $\mathrm{n}^{\circ}$ 179 e, segundo Loner et al. (2017), o início do trâmite de sua construção coincidiu com o fim da Revolução Farroupilha em 1845 e com o tráfico de escravos da África em 1850. A Câmara Municipal de Pelotas adquiriu o terreno que abriga o Mercado no ano de 1846.

O projeto foi idealizado pelo arquiteto Roberto Offer, posteriormente direcionado pelo mentor José Vieira Pimenta que também projetou a construção da cisterna dentro do Mercado tendo como mestre de obra Teodolino Farinha. Foi inaugurado em 1853, construído em estilo eclético com uma predominância colonial. Conforme aponta Loner et al. (2017), as paredes de alvenaria de tijolos, as pilastras e as portas dos quatro blocos se mantêm originais ainda hoje.

Na primeira versão do projeto não havia as quatro torres laterais, mas sim portões nas esquinas com formato de arco de meia circunferência que davam acesso ao interior do Mercado. Não fossem seus inúmeros portões poderia facilmente ser confundido com uma fortaleza capaz de armazenar até mesmo água potável. 
A principal função exercida no Mercado Central de Pelotas era a livre comercialização de produtos oriundos da região e até mesmo de outros estados e de países vizinhos como o Uruguai (ANTUNES \& HALLAL, 2016 p.3). Além de suas características funcionais de comércio, o pátio do Mercado também serviu de palco para artistas que circulavam pela cidade, tais como levantadores de pesos, homens voadores e/ou homens-bala.

O Mercado foi reformulado em 1914 projetada pelo engenheiro Manuel Barbosa Assumpção. O prédio ganhou traços e formas características do estilo Art Nouveau, os chanfros que abrigavam os portões de entrada foram substituídos por torres que passaram a marcar as esquinas, e os portões foram transferidos para o centro das quatro faces do prédio formando as entradas que permanecem até os dias atuais. Esta reforma também foi marcada pela troca da torre central, originalmente feita em alvenaria, que passou a ser uma torre de ferro inspirada na Torre Eiffel, fabricada na Alemanha por Luneburger \& Eisenwerk onde abriga no primeiro pavimento o reservatório de água. Junto com a torre foi instalada a cobertura de estrutura metálica em forma de cruz que cobre o Mercado no sentido Norte-Sul e Leste-Oeste, até os dias atuais.

Em 2002 iniciou-se uma revitalização, contemplada pelo Programa Monumenta do Governo Federal, que se estendeu até 2012 (ANTUNES \& HALLAL, 2016, p.3). Após a revitalização, o Mercado passou a ser abrigo de múltiplos comércios, em sua maioria são do ramo alimentício de caráter caseiro e natural, mas que conta também com comércio de artesanatos. O Mercado passou a ser um espaço frequentado por um tipo de público que busca além do comércio, conhecer a história da cidade e apreciar os eventos promovidos neste ambiente. Em pouco tempo a revitalização transformou o Mercado em um local aconchegante e resgatou a vontade da população e dos turistas de apreciarem o local. 


\subsubsection{Entrevistas}

Em razão dos novos usos, houve a necessidade de entender mais sobre a relação das pessoas com o ambiente e identificar as carências mais marcantes na sinalização do local a partir do ponto de vista dos permissionários ${ }^{[3]}$ que estão diariamente no MCP, bem como a percepção das pessoas que utilizam o local independente do uso. Para isso foi elaborado um roteiro de entrevista semiestruturada de natureza qualitativa aplicada aos permissionários do MCP. Também foi disponibilizado um questionário online via Google Forms com o intuito de atingir outros tipos de usuários de diferentes lugares da cidade.

As entrevistas semiestruturadas foram realizadas em abril de 2021 nas dependências do Mercado Central de Pelotas aplicadas com sete permissionários de diferentes segmentos e localização das bancas, de ambos os sexos com idades entre 40 e 80 anos. As respostas obtidas possibilitaram perceber que a dificuldade de orientação espacial dos frequentadores do Mercado é rotineira, visto que todos os permissionários entrevistados relatam que é comum e ocorre diariamente a procura por informações em suas bancas. Também é relatada a dificuldade que encontram em explicar o trajeto para os usuários muitas vezes necessitando sair da banca indo até o corredor para facilitar a explicação.

O questionário online foi realizado entre abril e maio de 2021 aberto a pessoas de qualquer faixa etária, gênero ou localidade, mas que preferencialmente conhecesse ou frequentasse o Mercado Central de Pelotas. Foram obtidas as respostas de cinquenta e nove participantes com idade entre 12 e 70 anos. Através das respostas obtidas, foi possível perceber que a dificuldade de orientação se estende à maioria dos respondentes que consideram importante a implementação de um Sistema de Sinalização no MCP. Do mesmo modo, foi possível identificar a maneira como esses usuários se orientam no Mercado, como circulam pelo ambiente, os marcos e pontos de referência e a maneira como utilizam o espaço.
[3] O termo "permissionários" refere-se aos locatários das bancas do Mercado Central de Pelotas. São os empresários/ comerciantes que tem permissão para comercializar seus produtos no MCP. 


\subsubsection{Levantamento Fotográfico}

No processo de pesquisa e levantamento de dados sobre o local, o reconhecimento do ambiente foi necessário para que pudesse obter uma percepção dos espaços disponíveis para a colocação das placas, observação dos detalhes arquitetônicos e identificação dos elementos que precisam ser sinalizados. Para isso, se fez necessário o levantamento fotográfico do MCP realizado em abril de 2021. As Figuras $1 \mathrm{e}$ 2 fazem parte deste levantamento e apresentam a parte externa e interna do Mercado.

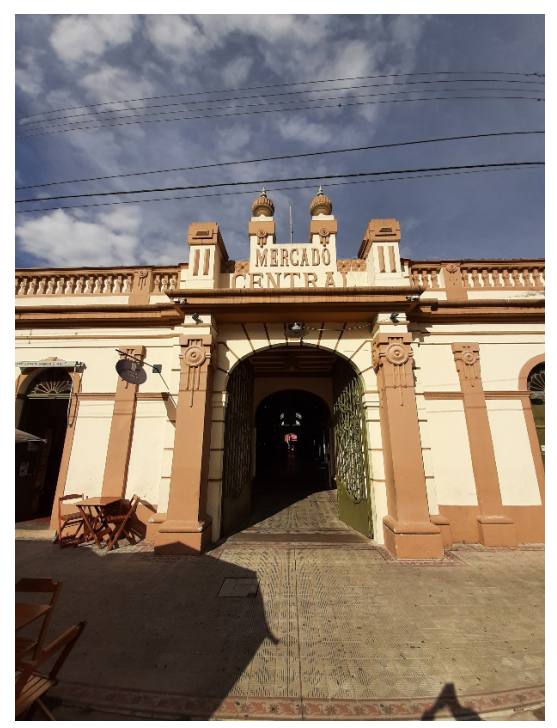

Figura 1 - Vista da entrada do MCP pelo Largo Edmar Fetter. Fonte: A autora, 2021

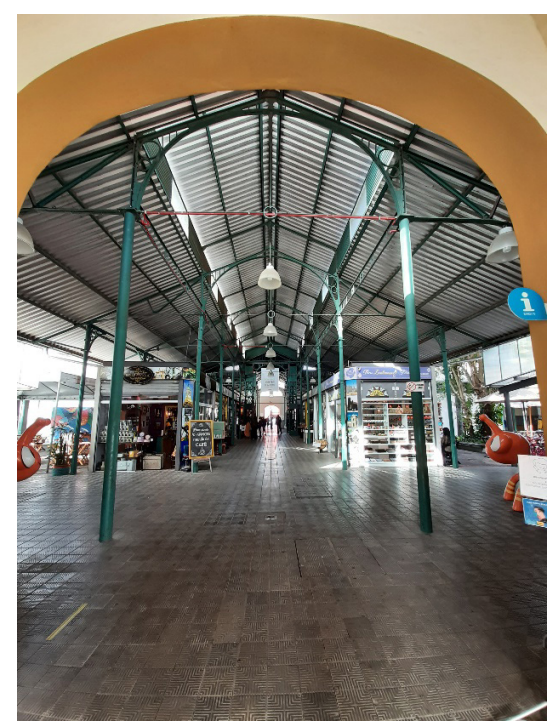

Figura 2 - Vista para o corredor central. Fonte: A autora, 2021.

\subsubsection{Análises}

A fim de identificar e compreender a sinalização atual do Mercado Central de Pelotas, foi elaborado uma análise levando em consideração os seguintes critérios que, segundo Corrêa (2015) compõem um Projeto de Sinalização: o sistema de signos de linguagem sintética (pictogramas); sistema de signos nominativos (tipografia); código cromático (cor); diagramação, entre outros. Estes critérios foram levados em conside- 
ração na análise do Mercado Central de Pelotas e na análise de similar feita no Mercado Municipal de Curitiba (MMC ${ }^{[4]}$. A análise comparativa foi realizada com o objetivo de compreender a estrutura da sinalização do local e identificar sua funcionalidade neste tipo de ambiente.

Mercado Central de Pelotas: Através dos levantamentos, identificação e avaliações realizadas foi possível perceber que a sinalização no Mercado Central de Pelotas é quase inexistente e carece de muitas informações. Igualmente se observou a falta de similaridade e regularidade entre as placas, muito provavelmente pelo fato de serem inseridas conforme as necessidades foram aparecendo. Além da falta de visibilidade que ocorre em alguns pontos, pode-se observar a degradação e falta de manutenção na maior parte das placas encontradas no MCP.

Mercado Municipal de Curitiba: A partir da análise feita na sinalização do Mercado Municipal de Curitiba, foi possível identificar aspectos que contribuem para a orientação espacial em um ambiente construído. A divisão dos espaços em setor A, B, $C, D$ e o uso das cores contribui para setorizar e formar zonas dentro de um espaço, facilitando a compreensão dos usuários diante das informações. O uso de mapas indicando a localização em que o usuário se encontra contribuem para a segurança nos momentos de tomada de decisão onde o usuário precisa identificar a direção a ser seguida para chegar até seu destino. Os sinais direcionais e pictogramas utilizados na sinalização facilitam a compreensão da direção indicada tornando o trajeto mais intuitiva e seguro.

Estas percepções em relação a sinalização do Mercado Municipal de Curitiba contribuíram para a reflexão no que se refere a escolha das estratégias a serem adotadas na elaboração do Sistema de Sinalização para o Mercado Central de Pelotas, como por exemplo a setorização dos ambientes. Essa e outras estratégias que serão apresentadas na sessão seguinte.
[4] O MMC foi escolhido por ser um Mercado Público em território nacional e pela disponibilidade de observar o interior do local através do Tour Virtual 360 disponibilizado em seu website. 


\subsection{ELABORAÇÃO PROJETUAL}

Esta seção aborda as etapas projetuais executadas na programação e na escolha das estratégias utilizadas para a elaboração do Sistema de Sinalização do Mercado Central de Pelotas, baseadas na metodologia proposta por Gibson (2009). Nesta etapa serão abordadas as Estratégias de Design utilizadas para o projeto, Proposta Gráfica e finalmente o Desenvolvimento, abrangendo a produção das placas, mockups, detalhamentos e manual.

\subsubsection{Estratégias de Design}

Esta etapa baseia-se nos levantamentos e resultados obtidos na etapa de pesquisa e análise possibilitando propor uma estratégia para o Sistema de Sinalização. Nesta etapa serão apresentadas as estruturas funcionais na qual são apontadas as propostas de organização do ambiente, estratégia de orientação e de indicação de bancas.

Estratégia de organização do ambiente: A estratégia adotada para organizar o ambiente foi dividir os espaços em sete zonas: Pátios 1, 2, 3, 4, Externa, Central e Neutra. Para D'Agostini (2017, p. 91) a zonificação cria "estratégias para meIhorar a circulação dos usuários, evitando que estes se percam ou demorem muito tempo na procura de um local específico dentro de um espaço maior".

A partir dessa proposta da divisão das zonas (Figura 3), foi possível traçar uma estratégia visual com uso de cores, criando associações com os espaços por meio da memória visual, estabelecendo a relação entre cor ao espaço para facilitar o processo do usuário de identificar a banca ou serviço que procura, a ser encontrada na zona representada por determinada cor.

No processo de desenvolvimento das estratégias de zonificação, percebeu-se a necessidade de identificar a Zona Central como forma de facilitar o reconhecimento do espaço assim como acontece com os Pátios 1, 2, 3 e 4. Esta percepção foi reforçada pelas sugestões apontadas nas entrevistas, sugerindo 


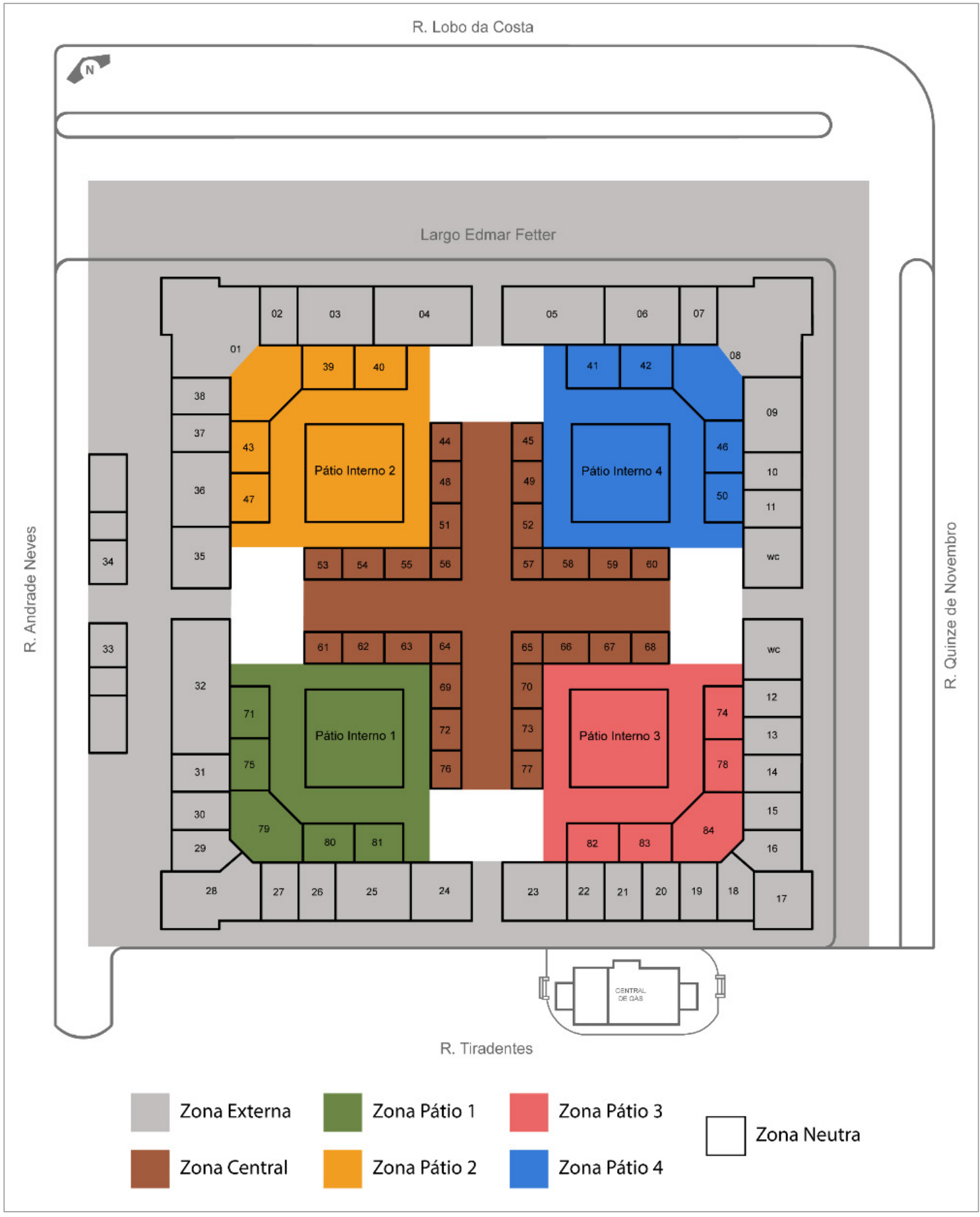

Figura 3 - Mapa proposta de zonas. Fonte: Elaborado pela autora, 2021.

que os corredores centrais, que lembram pequenas ruas ou travessas, fossem tratados de forma distinta. Para isso, através das pesquisas feitas sobre o Mercado identificou-se algumas histórias relacionadas ao local. Para a Travessa Leste-Oeste deu-se o nome de "Travessa das Quitandeiras" homenageando a atividade das quitandeiras que sempre foi forte no entorno 
do Mercado Central e assim, fazendo referência ao comércio. Para a Travessa Norte-Sul deu-se o nome de "Travessa da Cultura", este nome foi escolhido devido ao histórico cultural que sempre fez parte da atmosfera do MCP, dentre tantos artistas que se apresentaram ao longo dos anos no Mercado. Atualmente ainda é possível ver esta influência artística no local através dos músicos que tocam nos bares externos do Mercado, as rodas de samba, e os eventos como Feira do Livro e o Festival Internacional Sesc de Música, Moda Pelotas, entre outros.

Estratégia de orientação: Conforme as percepções da observação não-participante, das informações obtidas nas entrevistas aos permissionários e no questionário online, constatou-se que a maioria dos usuários utilizam as entradas como referência de localização. A partir dessa informação, foi definido a necessidade de incluir as indicações de saída junto a indicação da via externa situada na direção apontada. A maioria dos participantes das entrevistas e questionário respondeu que utilizam os corredores internos laterais quando precisam procurar algum serviço ou banca no interior do Mercado. Desta forma, estabeleceu-se que as orientações periféricas fossem guiadas através dos pátios diminuindo as chances do usuário se perder durante o trajeto, já que existem muitos "nós" ou pontos de decisão, que poderia tornar confusa a tomada de decisão contribuindo para a dificuldade de orientação. Sendo assim, os fluxos foram divididos com base na setorização das zonas (Figura 4). Esta estratégia busca otimizar o tempo gasto para que o usuário chegue até seu destino.

Estratégia de indicação das bancas: As bancas do MCP apresentam as numerações fixas, ou seja, mesmo que mude o nicho de serviço oferecido as numerações se mantêm, além da maioria das bancas popularmente serem indicadas pelo número junto com o nome. Por este motivo, no processo de escolha da hierarquia das informações nas placas optou-se por priorizar as numerações e manter o nome dos comércios de forma secundária. 


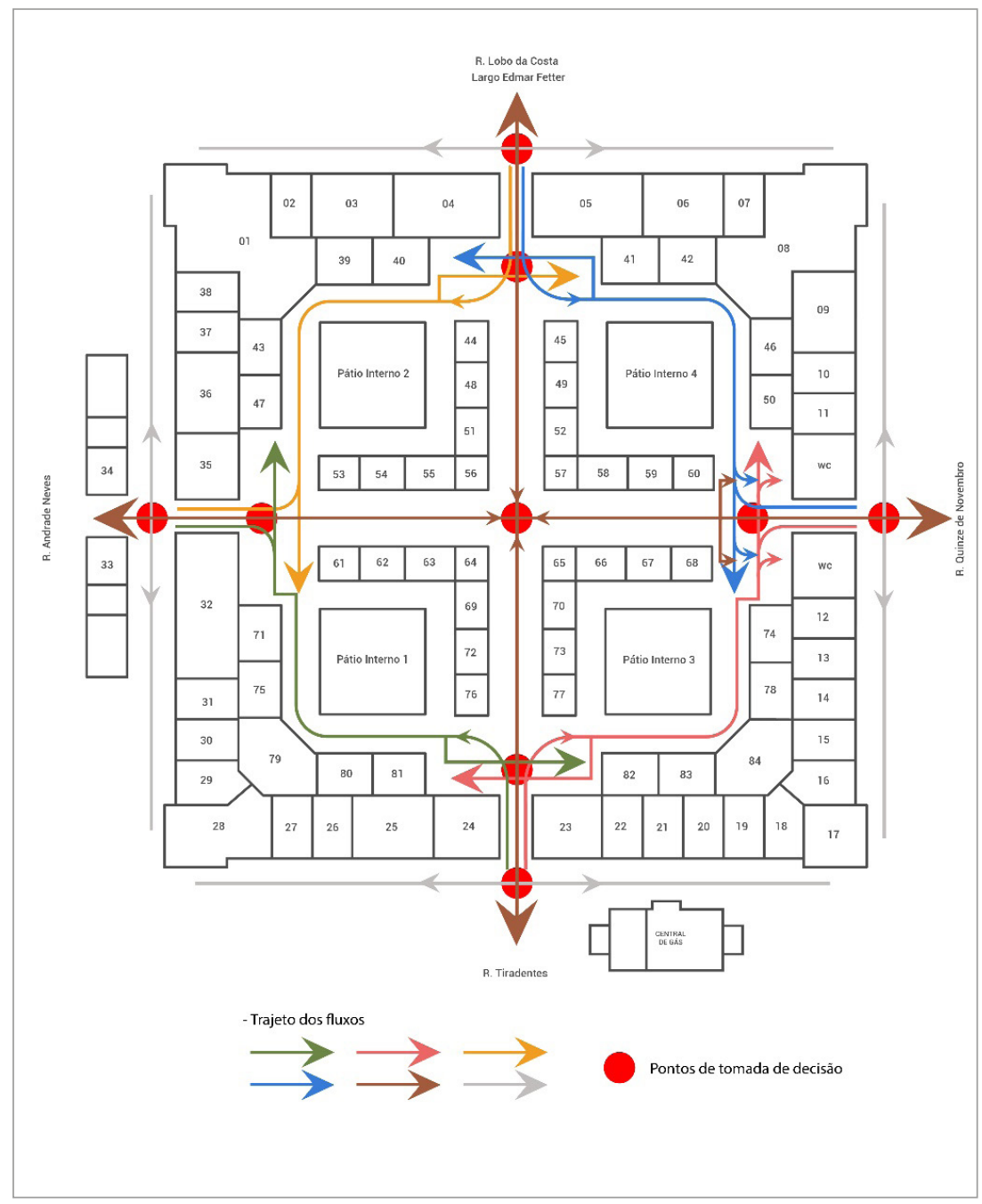

Figura 4 - Mapa de orientação e organização de fluxos. Fonte: Elaborado pela autora, 2021.

\subsubsection{Proposta Gráfica}

Esta etapa envolve a definição do conceito visual do projeto, a criação de paleta de cores, escolhas tipográficas, criação de pictogramas e escolha dos materiais. Para desenvolver esta etapa foram realizados levantamentos fotográficos dos prédios históricos da cidade, pesquisa de projetos de sinalização para painel inspiração e escolhas tipográficas, estudos e desenvolvimento de pictogramas baseados nas necessidades definidas no projeto. 
Conceito: Como primeiro movimento para a definição do conceito para a criação das placas e totens foram apontadas palavras-chave que representem a atmosfera que envolve o Mercado Central de Pelotas. Dentre as palavras-chave identificadas, algumas destacaram-se e influenciaram nas escolhas conceituais do projeto, são elas: Patrimônio, Turismo, Estrutura Metálica, Tradicional, Comércio, Compras, Largo, Pátios, Happy Hour, Memória, Convivência, Coração da Cidade, Cultura, Lazer e Lembranças.

Após a identificação e definição das palavras-chave, foi possível traçar o estilo visual adotado para o projeto, no qual optou-se por buscar um equilíbrio entre o tradicional e contemporâneo. O tradicional pelo fato de ser um local histórico cheio de personalidade e tradição; e contemporâneo com objetivo de transmitir de forma sutil os novos usos e estilos de ocupação de lugares que atravessam o tempo, como é o caso do MCP. As escolhas tipográficas e a elaboração dos pictogramas, contribuíram para que a composição visual da sinalização mantivesse este equilíbrio. Além disso, procurou-se intervir o menos possível nos elementos arquitetônicos históricos propondo fixações que não alterassem a estrutura em caso de retirada ou reformulação da sinalização.

Painel de Inspiração: Foi elaborado um Painel de Inspiração (Figura 5) com estilos de sinalização das quais serviram de inspiração e contribuíram para a escolha dos materiais, tipografias e pictogramas. As referências escolhidas para o painel partiram da definição do conceito do projeto que determina o equilíbrio entre o tradicional e contemporâneo, para isso, as escolhas basearam-se em projetos com a presença marcante do uso do metal, tipografias contemporâneas e pictogramas minimalistas.

\section{Relação da sinalização com a identidade arquitetônica:} Dentre as escolhas visuais do projeto definiu-se como muito importante a relação do Sistema de Sinalização com elementos arquitetônicos do MCP, com o propósito de que o Sistema fosse parte integrante do contexto, valorizando ainda mais 


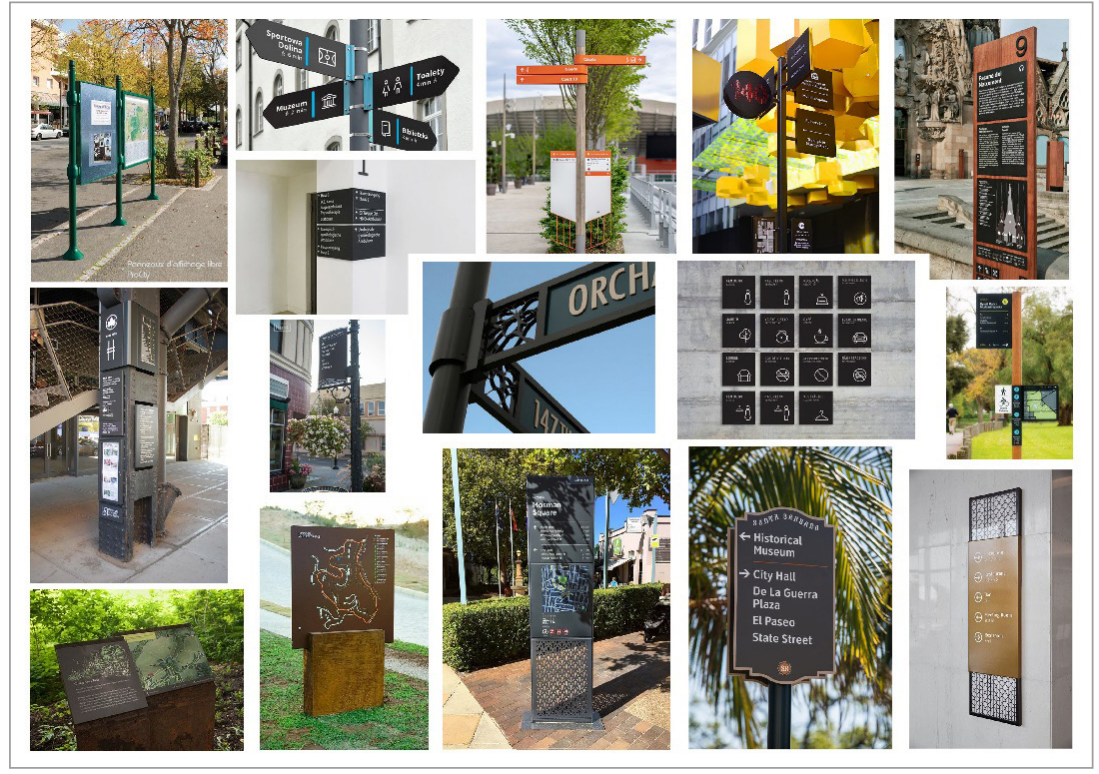

o espaço. A escolha dos materiais e formas partiu de uma referência a grande presença do ferro fundido, adaptado aos tempos atuais com alumínio em razão de ser mais leve e ter uma resistência maior a intempéries.

A inspiração para as formas surgiu dos desenhos em ferro dos portões que compõe as quatro entradas do MCP (Figura 6). Segundo Dametto (2009, p.58) O portão é originário de Bruxelas, Bélgica e claramente inspirado no estilo Art Nouveau, estilo este que também pode ser observado em detalhes nas fachadas do Mercado. Na Figura 07 é possível notar que o grafismo do portão é predominantemente composto por linhas curvas. Tal característica, serviu de inspiração para a definição das formas, escolhas tipográficas e desenvolvimento dos pictogramas.

Proporções, Formas, Grid e Diagramação: Durante o processo da escolha do portão como elemento de composição visual da Sinalização, buscou-se entender sua forma de composição. O primeiro passo (Figura 8) foi construir a proporção de retângulo áurea a partir do método de construção com quadrado. Em seguida, foi feita a construção da proporção em retângulo de raiz 2 também com método de quadrado.
Figura 5 - Painel de Inspiração. Fonte: Elaborado pela autora, 2021. Imagens: Pinterest. Caminho de busca: signage design. 


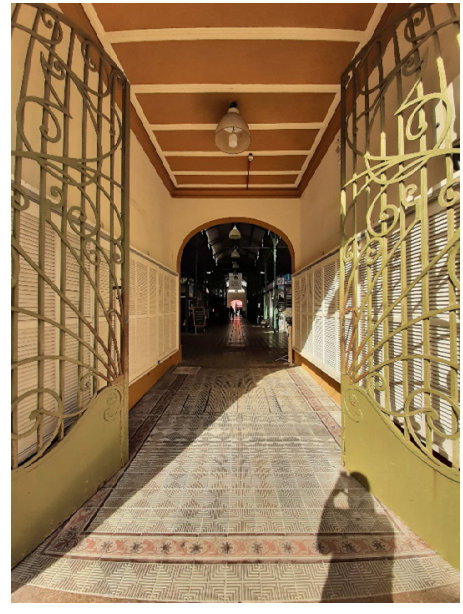

Figura 6 - Portão de ferro do Mercado Central de Pelotas. Fonte: A autora, 2021.

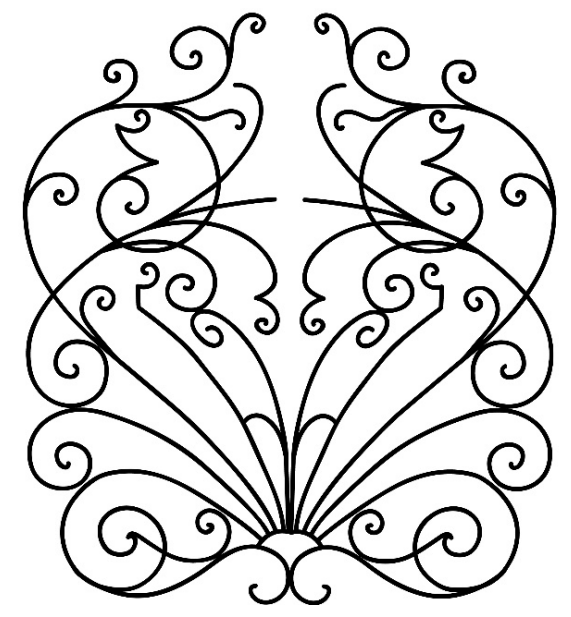

Figura 7 - Vetor do portão do MCP. Fonte: elaborado pela autora, 2021.

Após construir as duas relações de proporção, percebeu-se a necessidade de construir a proporção de retângulos áureos dinâmicos até a raiz 5, pois desta forma se relacionou melhor com a altura e largura do portão.
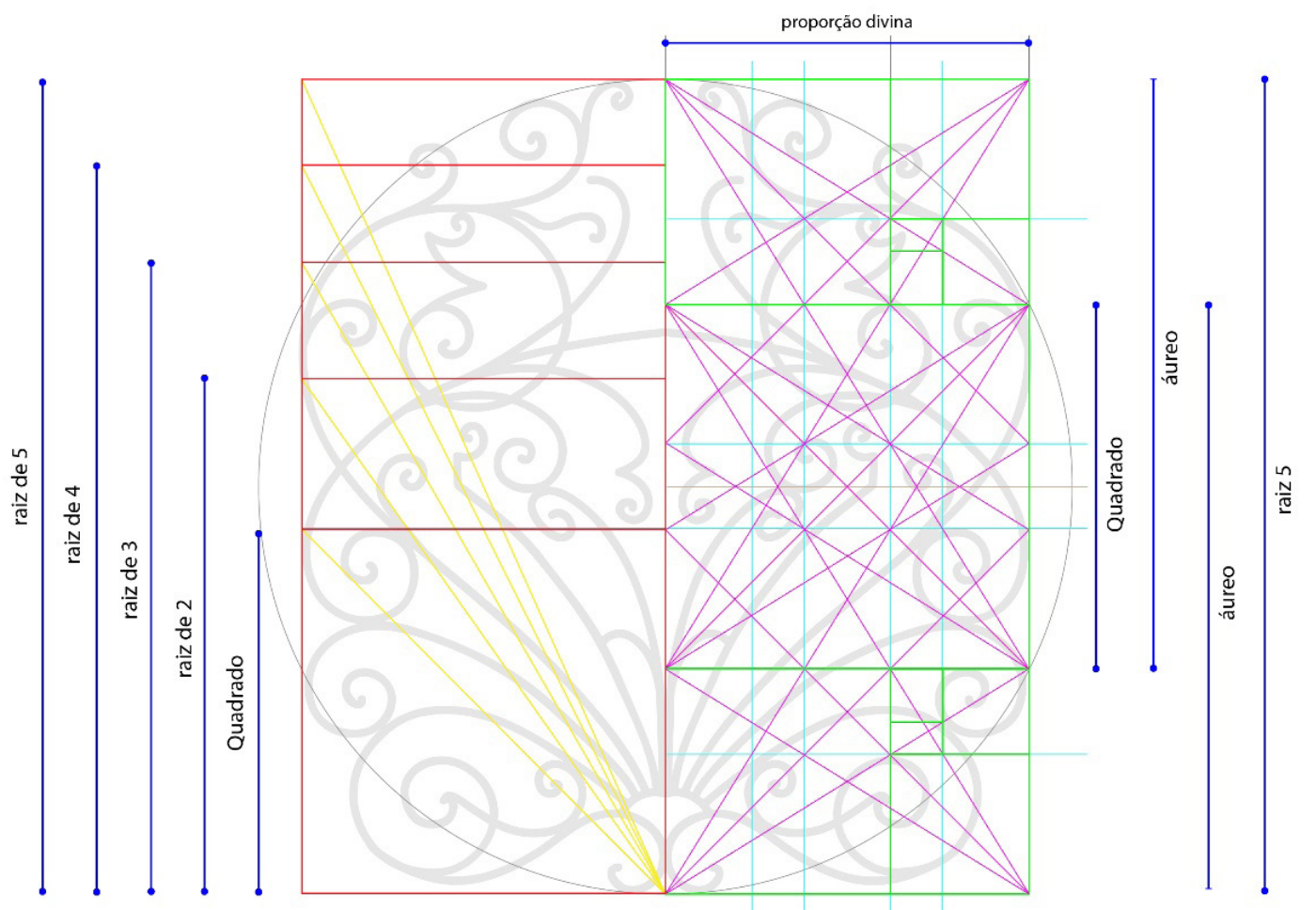

Figura 8 - Relação da raiz de 5, retângulo áureo e retângulos áureos dinâmicos. Fonte:

Elaborado pela autora, 2021. 
A partir destes estudos, utilizou-se a raiz de 5 como um norteador para a elaboração dos Totens de Bancas e Serviços e as Placas de Bancas e Serviços que são as placas direcionais com maior número de informações. Foi feito ainda o desdobramento de raiz recíproca para auxiliar a definir a diagramação das informações e signos (Figuras 9 e 10). As proporções serviram como guias de auxílio para a malha de construção (grid) (Figura 11) e não houve a intenção de utilizá-lo com um encaixe perfeito pois a quantidade e conteúdo das informações variaram muito em razão de seu posicionamento e direção.

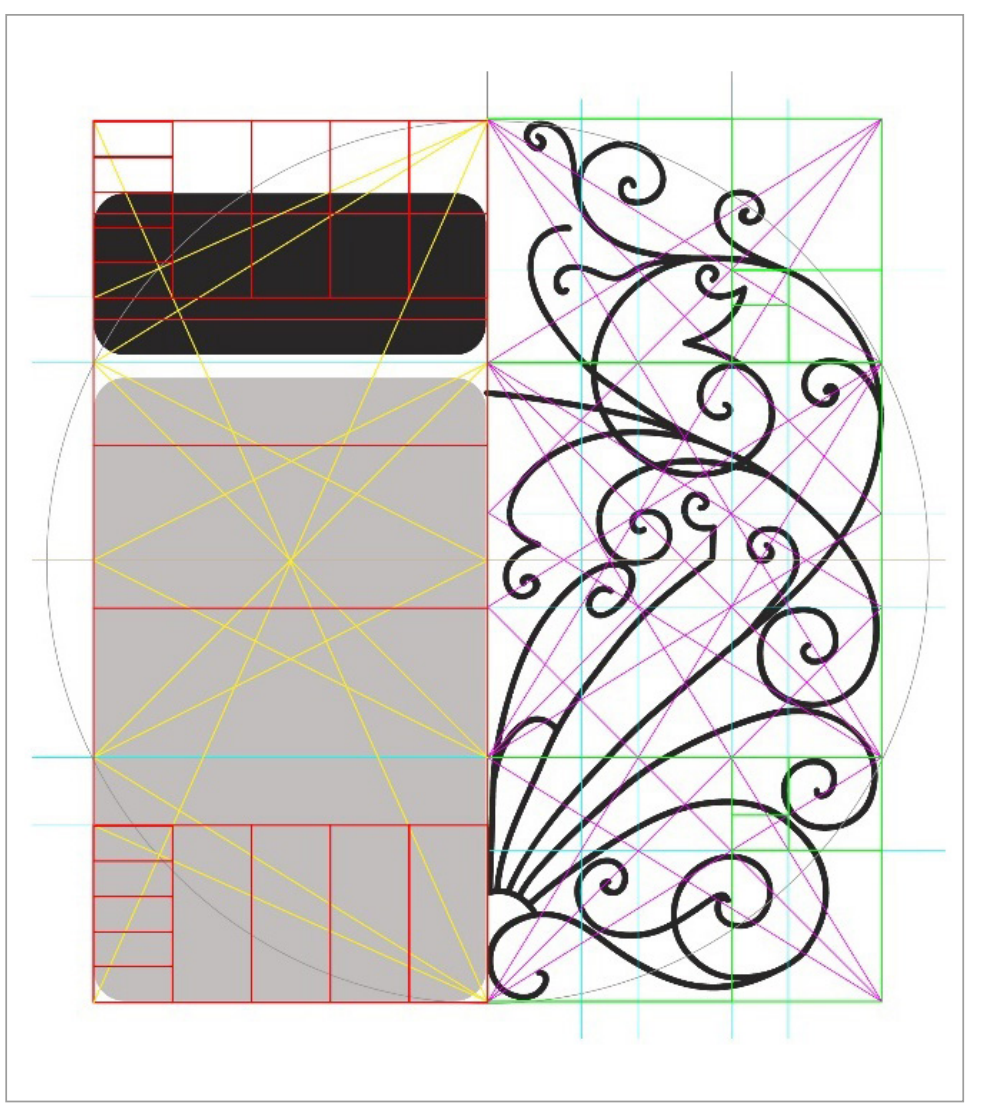

Figura 9 - Aplicação de raiz 5 em placa PLBS. Fonte: Elaborado pela autora, 2021.

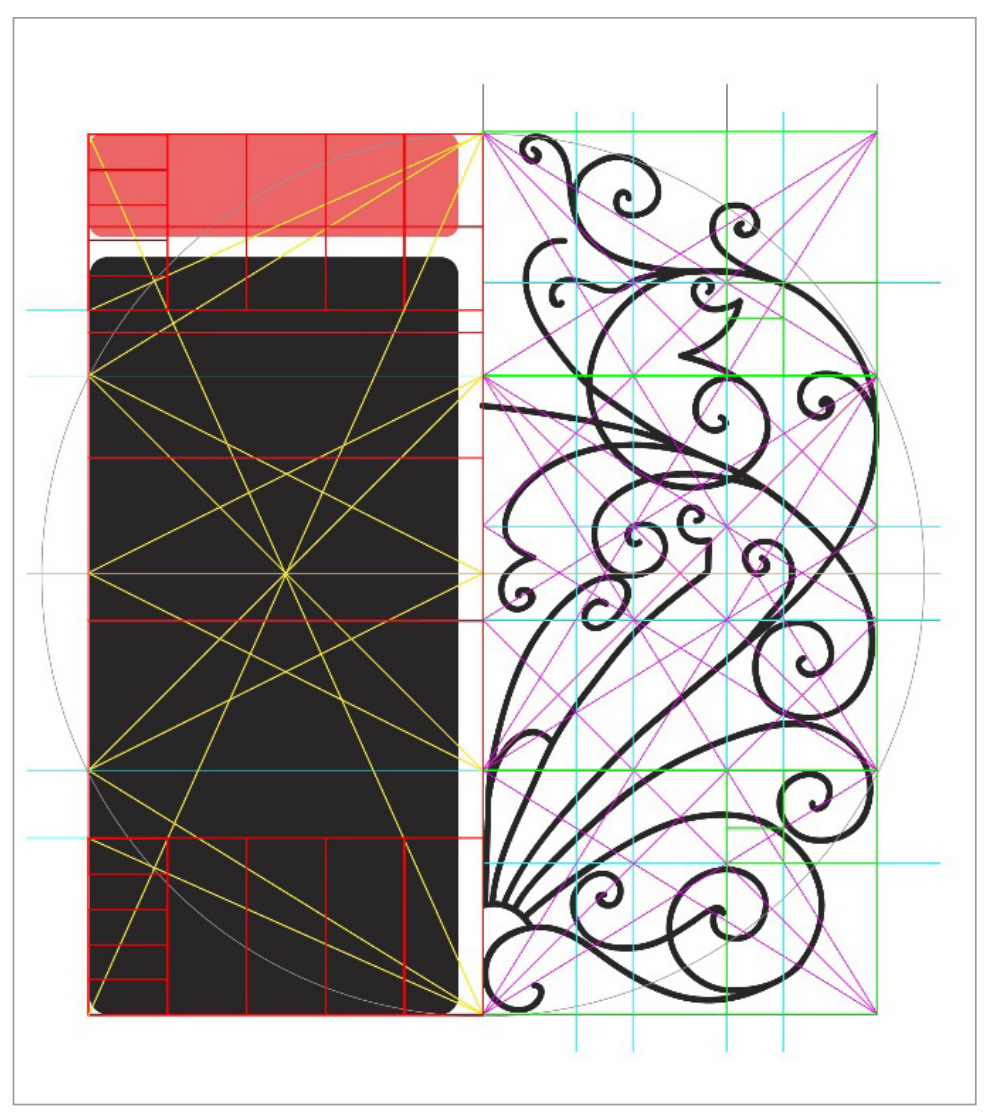

Figura 10 - Aplicação de raiz de 5 em placa TBS. Fonte: Elaborado pela autora, 2021. 


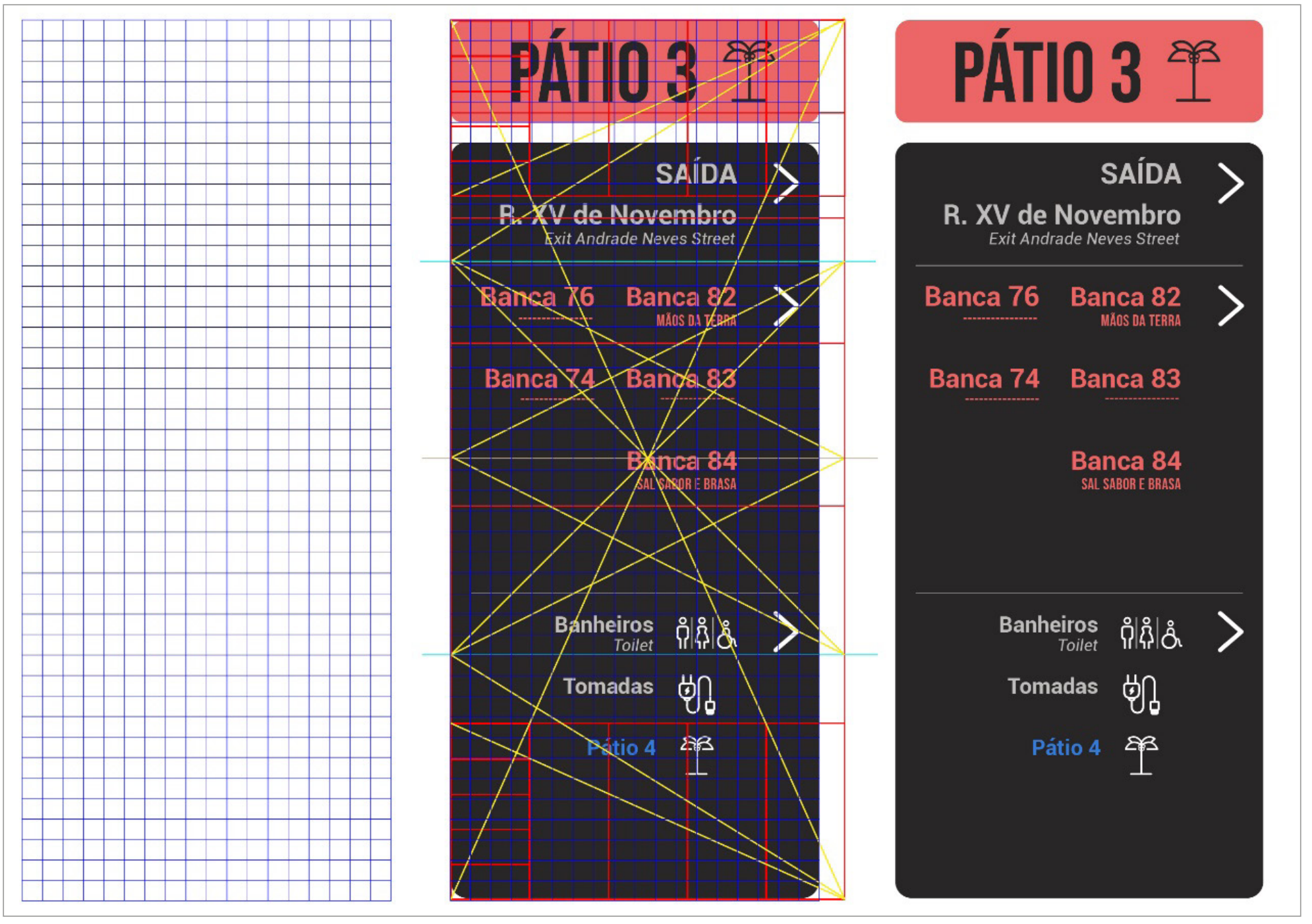

Figura 11 - Exemplo de aplicação de malha de construção. Fonte: Elaborado pela autora, 2021.

Segundo D'Agostini (2017, p.270) existem alguns aspectos que são determinantes para a compreensão das mensagens visuais expostas em um ambiente, entre eles estão: o contraste de cor entre suporte e informação, legibilidade da tipografia, reconhecimento dos pictogramas e sinais, entre outros. Porém, mesmo que esses princípios estejam funcionando de forma plena, se os elementos estiverem dispersos de maneira desordenada, a compreensão pode se tornar confusa. Por isso a hierarquia e sequência lógica de leitura deve ser organizada para que sejam percebidas com clareza. 
É possível encontrar diversas estratégias de organização das informaç̃̃es visuais como: as malhas de construção (grid), alinhamentos, agrupamentos, hierarquia, proporção e composição.

No processo de diagramação da sinalização do MCP as estratégias citadas acima foram utilizadas de forma conjunta. Inicialmente definiu-se a estratégia de hierarquia para definir quais informações teriam maior relevância. Em seguida definiram-se as proporções dos elementos visuais com base na definição da hierarquia e, por conseguinte, os agrupamentos foram feitos definindo os módulos das informações. Posteriormente a essas definições foi possível aplicar a malha de construção (grid) para, por fim, definir os alinhamentos. A construção do grid partiu da definição da área de um quadrado de $4 \mathrm{~cm}$ por $4 \mathrm{~cm}$, podendo variar proporcionalmente conforme o tamanho de cada tipo de placa. A construção do grid também serviu de base para a elaboração dos pictogramas com o intuito de harmonizar as proporções e relacionar com as demais escolhas de projeto.

Paleta de cores: A escolha da paleta foi definida a partir das cores aplicada na pintura nos prédios históricos que se encontram no entorno do Mercado Central de Pelotas e da praça Coronel Pedro Osório. Foi realizado um levantamento fotográfico dos prédios e, a partir disso, a coleta das cores da fachada e seleção das cores (Figura 12) que contrastassem com as do Mercado para que houvesse destaque e fosse possível diferenciar e identificar a sinalização no ambiente. Após a definição das cores optou-se por aumentar sua saturação para realçar as tonalidades.

PANTONE 575 UP C61 M30 Y90 K12

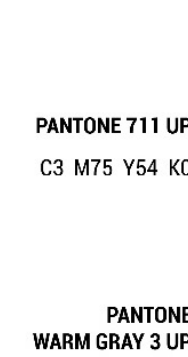

C24 M21 Y21 K0
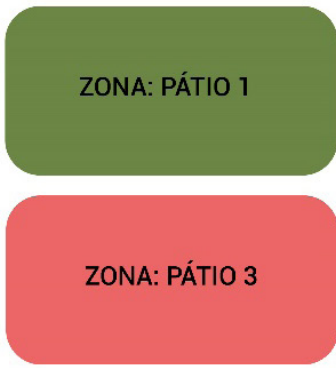

ZONA: ÁREA EXTERNA E TIPOGRAFIAS

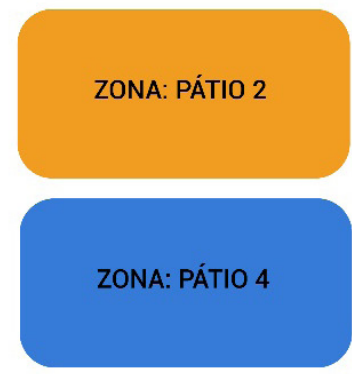

PANTONE 138 UP C3 M44 Y98 K0

PANTONE 7684 UP C76 M50 Y0 K0

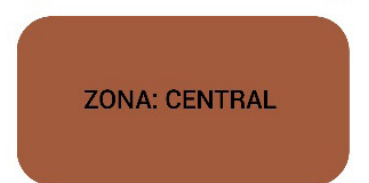

PANTONE 7526 UP C28 M69 Y81 K17

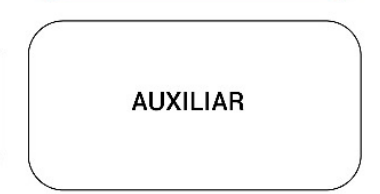

Figura 12 - Paleta de cores. Fonte: Elaborado pela autora, 2021. 
Tipografia: Para Scherer (et al., 2017, p.4) "a escolha do tipo ou da família tipográfica a ser usada, deve levar em conta aspectos conceituais como a adequação ao ambiente e a mensagem a ser transmitida assim como os aspectos técnicos como a legibilidade".

A tipografia Roboto (Figura 13) foi escolhida por ser uma fonte com boa legibilidade, moderna e tem uma família de estilos de fonte completa permitindo o uso da mesma tipografia para informações com pesos diferentes sendo utilizada para os textos descritivos das placas e totens como: saídas, ruas, bancas, pontos turísticos, serviços e informações gerais. Além disso, é possível observar nas letras $\mathbf{t}$ e $\mathbf{f}$ minúsculas a curvatura na base e no ascendente, tal característica serviu de referência para o desenho dos pictogramas e para a definição do formato geral das placas e totens. A escolha da Roboto contribuiu para que o projeto afirmasse a linha conceitual contemporânea.

\section{Roboto Thin \\ Roboto Thin Italic \\ Roboto Light \\ Roboto Light Italic \\ Roboto Regular \\ Roboto Regular Italic \\ Roboto Medium \\ Roboto Medium Italic}

Roboto Bold

Roboto Bold Italic

Roboto Black

Roboto Black Italic

Roboto Condensed

Roboto Condensed italic

Roboto Condensed Bold

Roboto Condensed Bold Italic

Figura 13 - Roboto. Elaborado pela autora, 2021.

A Bebas Neue (Figura 14) foi escolhida por sua presença robusta e condensada, permitindo fazer um contrapeso com a Roboto e garantindo um destaque para as informações sendo utilizada para textos de informação rápida e destaque, como: títulos, nome dos comércios e números das bancas. Assim como a Roboto, a Bebas Neue contribuiu para que fosse possível criar um contraste entre a sinalização e ambiente. 


\section{BEBAS NEUE}

VERSION $2 . X X X$

Figura 14 - Bebas Neue. Fonte: Github, 2021.

Pictogramas: Conforme apontado pelo autor D'Agostini (2017, p.106), uma família de pictogramas deve ser capaz de atender satisfatoriamente pelo menos três níveis:

1. Estético - Adequar-se à estética e à linguagem do local e/ou da comunicação;

2. Cultural - Ser compreendido enquanto elemento que compartilha dos mesmos códigos de linguagem dos usuários do ambiente;

3. Regulamentar - Estar de acordo com as normas e regulamentações do espaço em que serão implementos.

A definição dos pictogramas (Figura 15) foi elaborada conforme as necessidades identificadas no projeto. Além dos sinais de seta e sinais normativos foi necessário a construção de pictogramas específicos para alguns espaços e situações como a representação das Tampinhas, Peixarias, Açougue, Deus Mercúrio, Formigas, Largo Edmar Fetter, Bará, Pátios e a Torre.

Graficamente optou-se pela construção em linhas finas com o intuito de suavizar os detalhes e tornar mais inteligível. A fim de familiarizar os pictogramas com a escolha tipográfica e com a relação da linha arquitetônica definida para o projeto, optou-se por construir os pictogramas com cantos arredondados buscando suavidade, leveza e modernidade. Para a cons- 

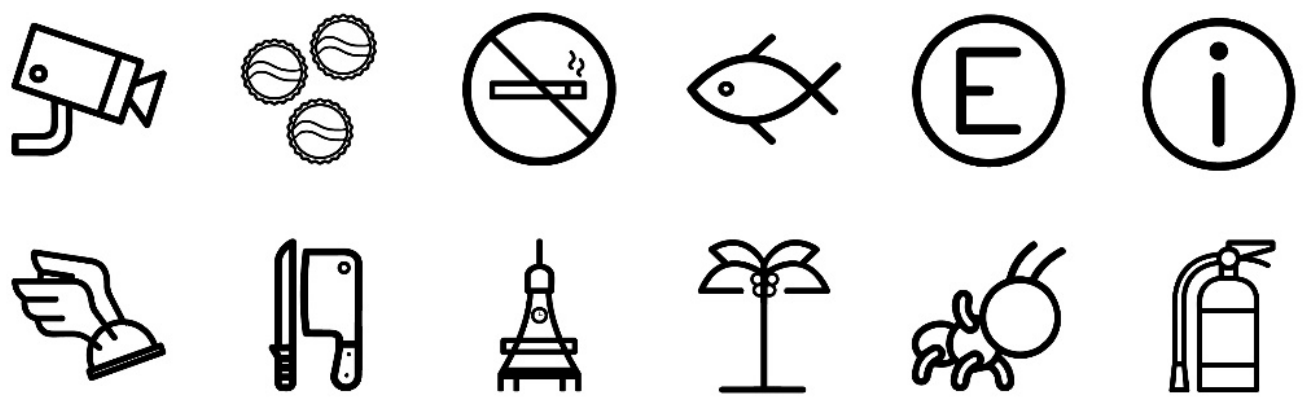

路
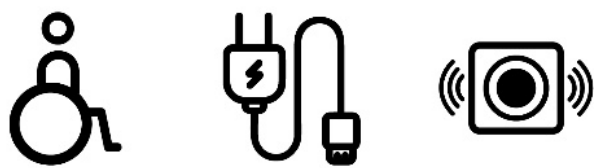

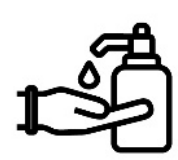

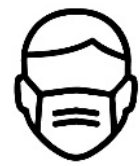
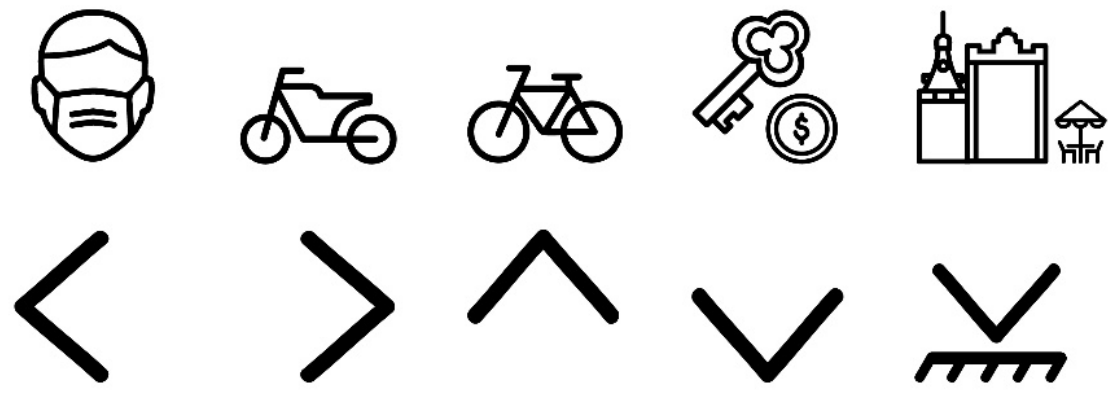

trução das setas direcionais optou-se por manter linhas mais grossas para melhorar a visualização na composição das placas. Todos os pictogramas foram construídos a partir do grid estabelecido para diagramar as informações nas placas e totens.

\subsubsection{Desenvolvimento da Sinalização}

A etapa de desenvolvimento sugerida por Gibson (2009), contempla a elaboração das peças que compõem o Sistema de Sinalização. Conforme a metodologia aplicada no projeto, o resultado das peças representa a somatória dos estudos conceituais, bibliográficos e técnicos apresentadas nas seções anteriores.

Foram desenvolvidos ao total dezesseis modelos de sinalização. As peças visam a padronização entre tipologias semeIhantes e podem ser replicadas apenas alterando as informações previamente organizadas no manual onde encontram-se as especificações completas. 
Na Figura 16 é possível observar a altura e proporção do conjunto de sinais em relação à escala humana. As placas apresentadas nessa figura servem apenas para representar o modelo de cada tipo de sinal sendo que as demais podem ser vistas no Manual de Sinalização e Wayfinding.

Figura 16 - Conjunto de Sinais. Fonte: Elaborado pela autora, 2021.
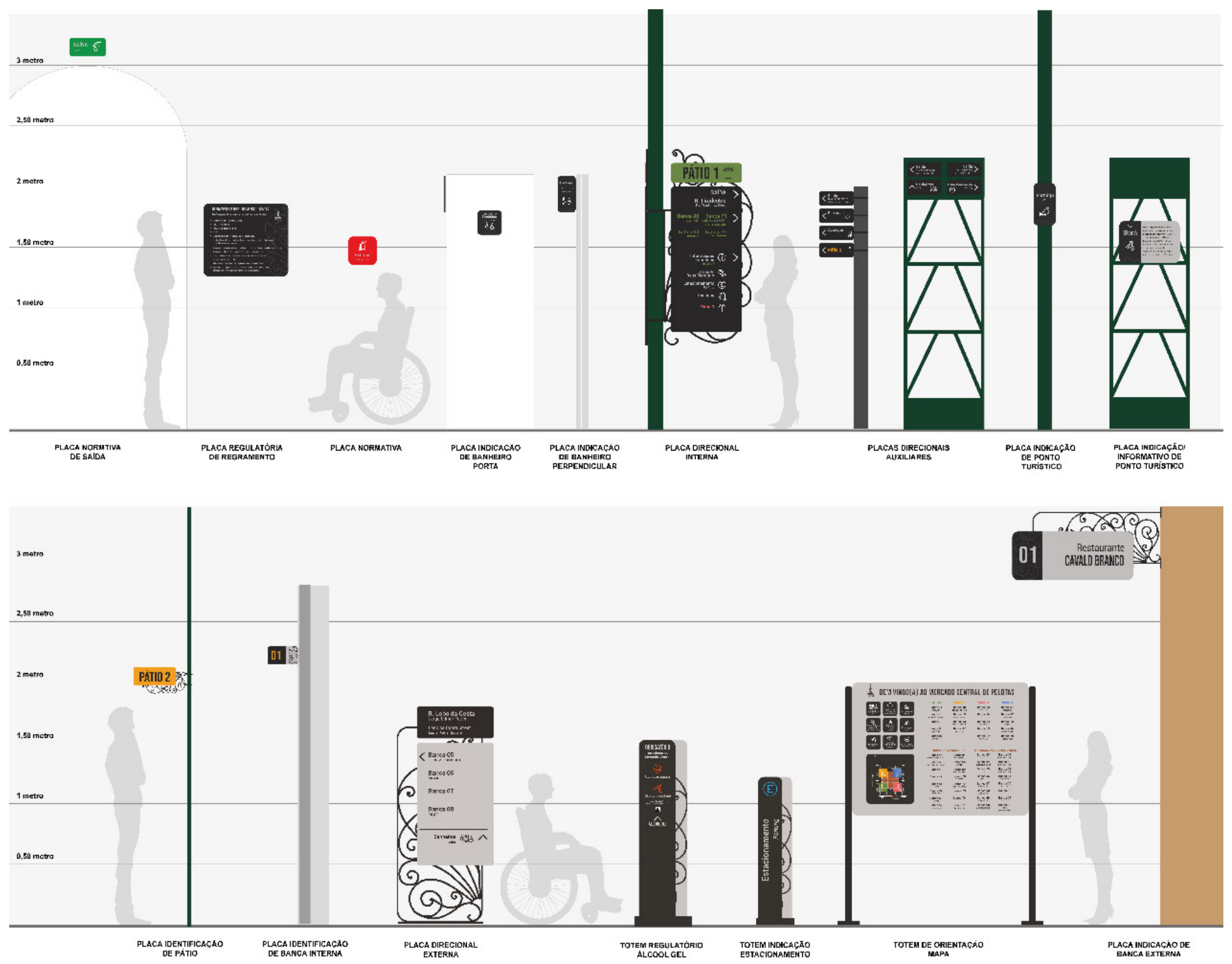

$\begin{array}{lllll}0 & 0.5 & 1.0 & 1.5 & 2.0 \\ \longmapsto & \text { Metros }\end{array}$ 
Como exemplo de detalhamento, a Figura 17 representa o modelo de Placa Direcional Interna Contém indicação dos Pátios ou Travessas, indicações das saídas e respectivas ruas adjacentes informadas em dois idiomas. Conta também com indicação das bancas e serviços encontrados nas respectivas direções. O Posicionamento das placas previstas para o lado interno do Mercado dispostas no hall das quatro entradas (Figura 18). Cada entrada contará com quatro placas, duas indicando para as Travessas e as outras duas indicando para os Pátios opostos. O mockup (Figura 19) apresenta as placas localizadas no lado direito do hall de entrada pela rua Andrade Neves.
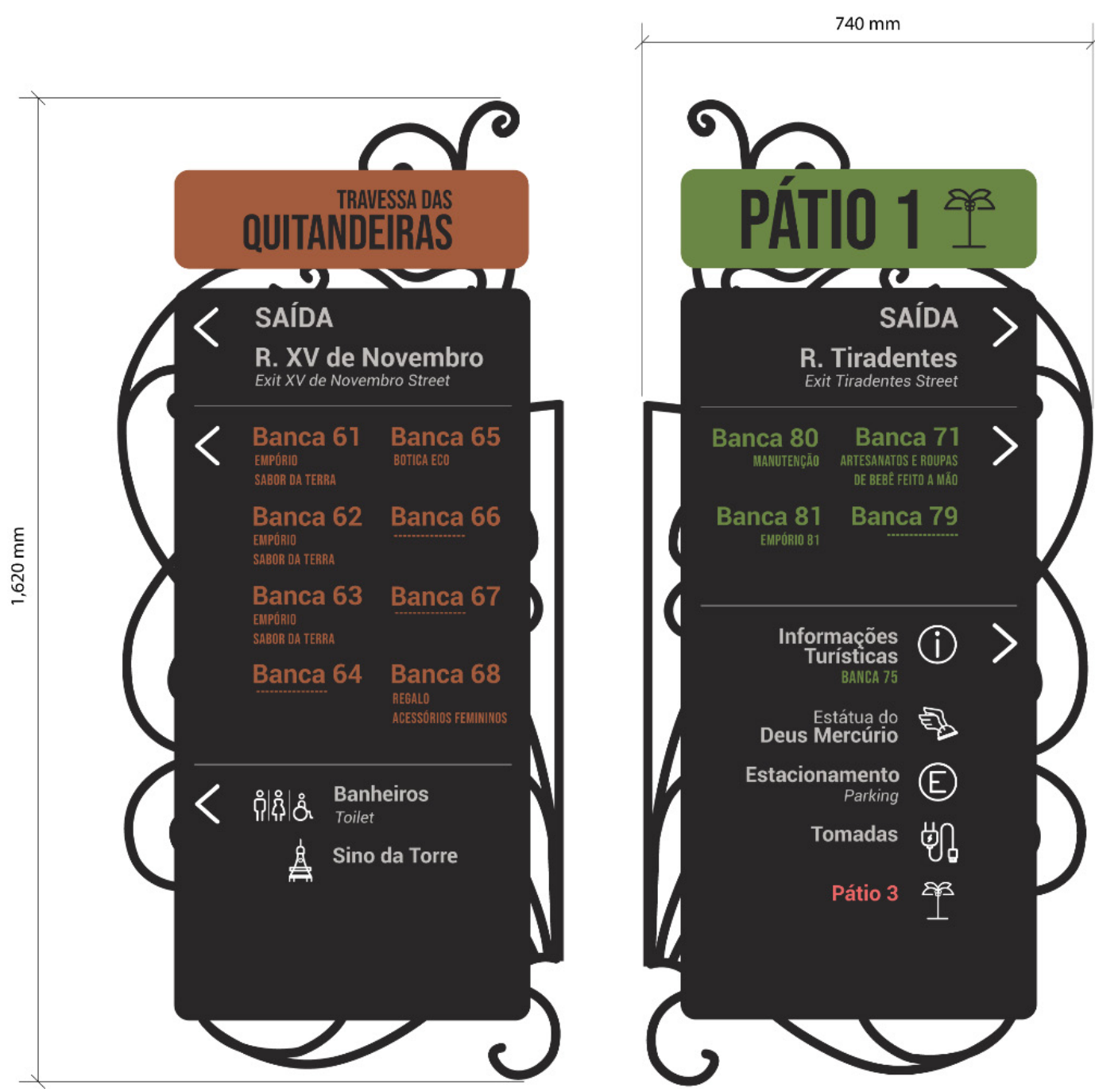

Figura 17 - Modelo placa direcional interna. Fonte: Elaborado pela autora, 2021. 


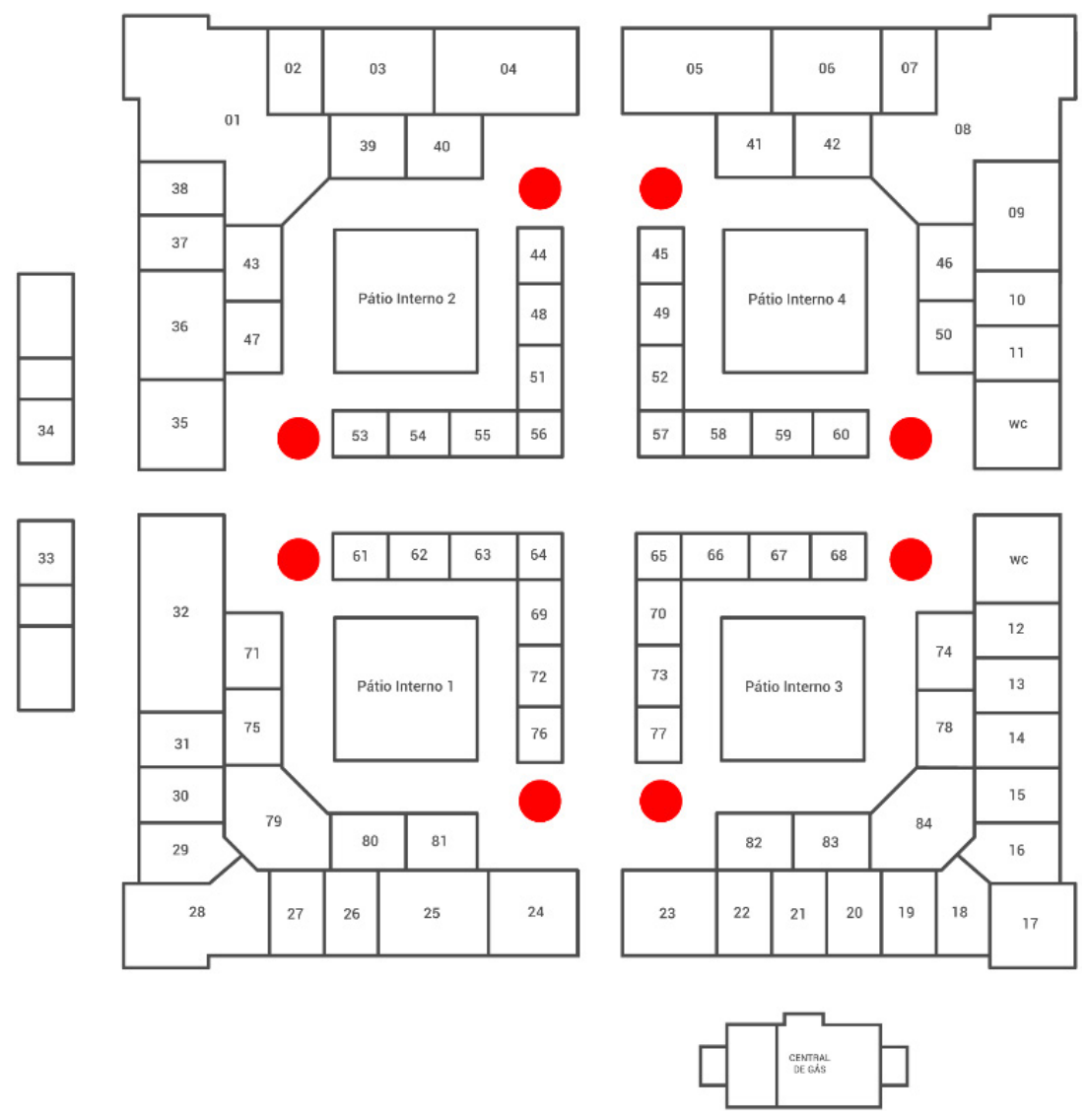

Figura 18 - Mapa de posicionamento das placas. Fonte: Elaborado pela autora, 2021.

$\mathrm{Na}$ etapa de desenvolvimento buscou-se contemplar todas as necessidades identificadas ao longo do estudo e dos levantamentos feitos a respeito do Mercado Central de Pelotas.

Considerando que o MCP é um ponto turístico da cidade, optou-se por disponibilizar apoio bilíngue para alguns tipos de informações. Todas as placas normativas, placas de indicação de ponto turístico e totem de estacionamento recebem apoio bilíngue. Nas demais placas optou-se por trazer em algumas informações que foram eleitas como mensagem de tomada de decisão rápida, são elas: saídas, nome das ruas, informações turísticas e banheiros. 


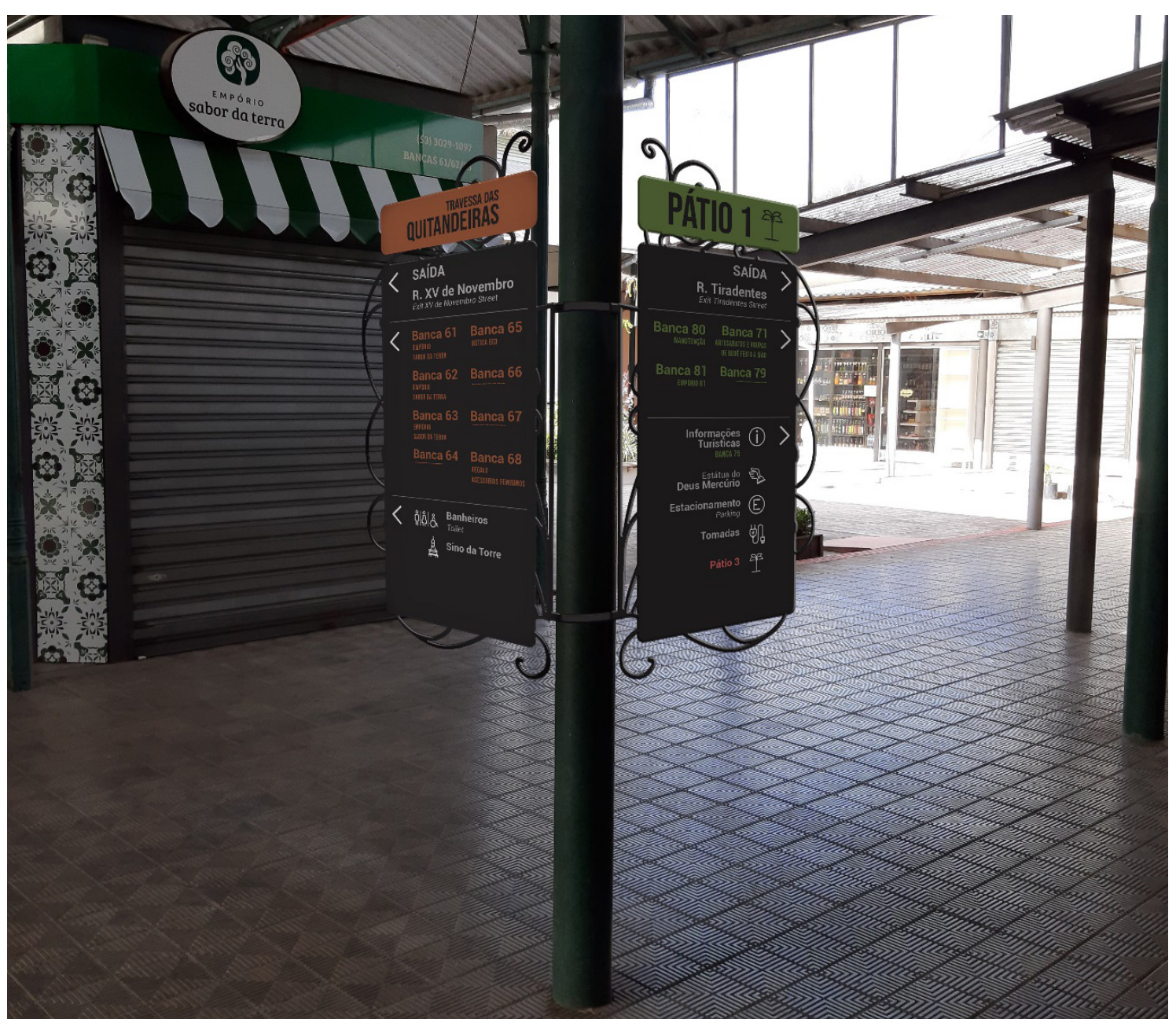

Figura 19 -Mockup placa direcional interna. Fonte: Elaborado pela autora, 2021.

Materiais: Para o projeto de sinalização do Mercado entende-se que a escolha adequada seja a utilização de materiais resistentes a umidade e intempéries, que tenham fácil aceitação dos acabamentos propostos e um bom custo-benefício a longo prazo. Entre as principais escolhas estão:

Alumínio: A proposta prevê que as placas de sinalização sejam produzidas em alumínio, tanto as placas quanto as estruturas de apoio e sustentação. D'Agostini (2017) comenta que o alumínio se difere de outros tipos de ligas de aço não necessitando de tratamentos específicos para retardar o processo de corrosão pois já possui propriedades anticorrosivas em sua composição, além de ser um material leve, resistente, reciclável e de fácil conformação. O ACM (Aluminium Composite Material), apesar de possuir propriedades próximas à chapa de alumínio sólido foi descartado em razão da grande quantidade do curvas, dobras e retornes necessários para esconder as bordas. 
Acrílico: O acrílico que será utilizado para a produção das placas de regramento é um material leve, resistente e de fácil manipulação. As placas de regramento serão as únicas fixadas nas paredes através de parafusos, por isso optou-se por um material mais leve que alumínio e que também apresenta resistência a intempéries e é reciclável.

Adesivo vinílico: Utilizado para os elementos informativos das placas. É um material que possui fácil manutenção e possibilidade de troca das informações quando necessário. O processo de retirada do adesivo não danifica a superfície e em consequência aumenta a vida útil das placas.

Fixação - Abraçadeiras e adesivo dupla face: A escolha desses materiais para a fixação da maioria das placas partiu da decisão de intervir o menos possível na estrutura do local. Por se tratar de um prédio histórico optou-se por preservar a sua integridade o máximo possível.

\subsubsection{Documentação}

A última etapa projetual refere-se à criação do Manual do Sistema de Sinalização e Wayfinding ${ }^{[5]}$. O desenvolvimento do Manual visa regulamentar a construção física do Sistema de Sinalização projetado para o Mercado Central de Pelotas contendo todas as diretrizes e etapas projetuais, bem como os resultados práticos obtidos, estratégias gráficas, relação de materiais, ambientações e desenhos técnicos.

No Manual de Sinalização e Wayfinding Mercado Central de Pelotas, é possível conhecer por completo as ambientações, detalhamento de material, acabamento e construção de cada modelo desenvolvido. Ao final, estão apresentadas todas as placas e totens desenvolvidos com suas respectivas informações. Totalizando dezesseis modelos de placas sendo eles: Totem mapa (TM); Totem bancas e serviços (TBS); Totem estacionamento (TE); Totem álcool gel e máscara (TAM); Placas de bancas externas (PLBE); Placa de bancas internas(PLBI); Placa de bancas e serviços (PLBS); Placas de pátio (PLP); Placas auxiliares (PLA); Placas de serviço (PLSE); Placas de sa-
[5] Disponível no formato digital através do seguinte endereço: https://bit.ly/manual sinalizacao_wayfinding_mcp 


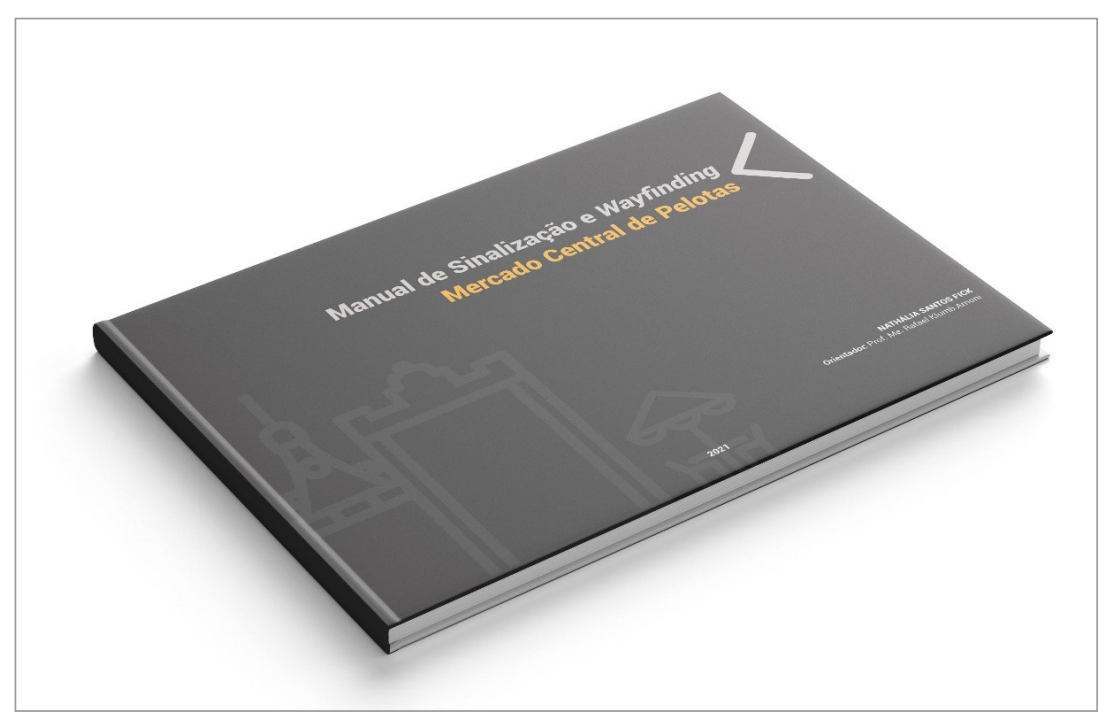

Figura 20 - Capa Manual de Sinalização e Wayfinding. Fonte: Elaborado pela autora, 2021.

ída (PLSA); Placas de regramento (PLR); Placas de ponto turístico (PLT); Placas de ponto turístico informativo (PLTI); Placa de banheiro (PLSB); Placa de banheiro perpendicular (PLSBP). Foi necessário ainda replicar alguns dos modelos para contemplar as informações disponíveis e indicadas na direção da zona totalizando 161 sinais desenvolvidos no projeto.

\section{CONSIDERAÇõES FINAIS}

O projeto procurou melhorar a orientação para os usuários, minimizando problemas causados especialmente pela simetria arquitetônica característica do local e pela falta de informações disponíveis no ambiente. A utilização da metodologia proposta por Gibson (2009) proporcionou a organização dos processos de estudo e coleta de dados essenciais para a elaboração de um Sistema de Sinalização para o Mercado Central de Pelotas e por fim, o desenvolvimento do Manual de Sinalização e Wayfinding.

A principal estratégia utilizada foi a proposta de divisão por zonas tirando proveito dos nichos formados pelos pátios internos e a centralização dos corredores favorecendo a con- 
figuração por zonas. Para auxiliar os usuários a conectar os espaços e suas informações, foi determinado que cada zona seria caracterizada por cores distintas, com o intuito de fazer com que o usuário distinguisse os espaços, provocando-os a criar um mapa mental do ambiente e consequentemente conseguir relacionar a sua posição em relação ao espaço.

Considera-se que este artigo possa colaborar com futuros estudos no meio acadêmico contribuindo para o processo de pesquisa e criação de projetos de sinalização. Espera-se que através deste estudo sejam despertados os olhares e o interesse da comunidade acadêmica em propor soluções para problemas identificados em espaços públicos principalmente nos que dizem respeito ao patrimônio cultural que muitas vezes acaba por ficar no esquecimento.

\section{REFERÊNCIAS BIBLIOGRÁFICAS}

ANTUNES, Roberta, HALLAL,Dalila. O projeto de revitalização do Mercado Público de Pelotas: algumas críticas da comunidade local. EmiCult. Pelotas: UFPEL, 2016.

BAUMANN, Sander. Introduction to wayfinding and signage design. Publicado em 15.nov.2010. Disponível em: http://www.designworkplan.com/wayfinding/ introduction.htm Acesso em: 14 Nov. 2019.

CARDOSO, Eduardo; SCHERER, Fabiano de Vargas; TEIXEIRA, Fábio Gonçalves; SILVA, Régio Pierre da; SILVA, Tânia Luisa Koltermann da. Contribuição metodológica em design de sinalização. InfoDesign:., Porto Alegre, ano 2011, v. 8, ed. 1, p. 10-30, 2011.

CHAMMA, Norberto; PASTORELO, Pedro Dominguez. A justa medida da sinalização. InfoDesign: Revista Brasileira de Design da Informação. 2008, Vol. 5 Issue 1, p72 - 74. 3p. 
CORRÊA, Bruno de Souza. A metodologia de design aplicada a sistemas de sinalização: o briefing. Cadernos UniFOA

Especial Design, Volta Redonda, n.2, p.25-33, jan. 2015.

D'AGOSTINI, Douglas. Design de Sinalização.

São Paulo: Blucher: 2017.

DAMETTO, Ana Paula de Andrea. Os metais no

Patrimônio Arquitetônico urbano de Pelotas, RS - 1870

a 1931. Dissertação de mestrado em Memória Social

e Patrimônio Cultural. Pelotas, UFPel,2009. Disponível

em: https://wp.ufpel.edu.br/ppgmp/files/2016/11/

Ana-Paula-Dametto.pdf. Acesso em: 15 Jul. 2021.

GITHUB. Bebas Neue. [s.I]. Disponível em: https://github.com/

dharmatype/Bebas-Neue\#readme> Acesso em: 06 Jul. 2021.

GIBSON, David. The Wayfinding Handbook. New

York: Princeton Architectural Press, 2009.

LOCATELLI, L. Orientação espacial e características

urbanas. Dissertação em Planejamento Urbano

e Regional. Porto Alegre: UFRGS, 2007.

LONER, Beatriz Ana; GILL, A. Lorena; MAGALHÃES,

O. Mario (organizadores). Dicionário de histórias

de Pelotas. 3. Ed. - Pelotas: Editora da UFPel

(FAU - Fundação de Apoio Universitário), 2017.

SCHERER, Fabiano de Vargas. (tese de doutorado).

Sistematização e proposição de Metodologia

de projeto para sinalização espaço - usuário -

informação. Porto Alegre: UFRGS/PGDESIGN, 2017.

SCHERER. Fabiano de Vargas; CATTANI, Airton;

SILVA, Tania Luisa Koltermann da. O papel do

usuário em metodologias de projetos de sinalização.

Infodesign: Revista Brasileira de Design da

Informação, São Paulo, v.14, n.2, p.172-186, 2017. 